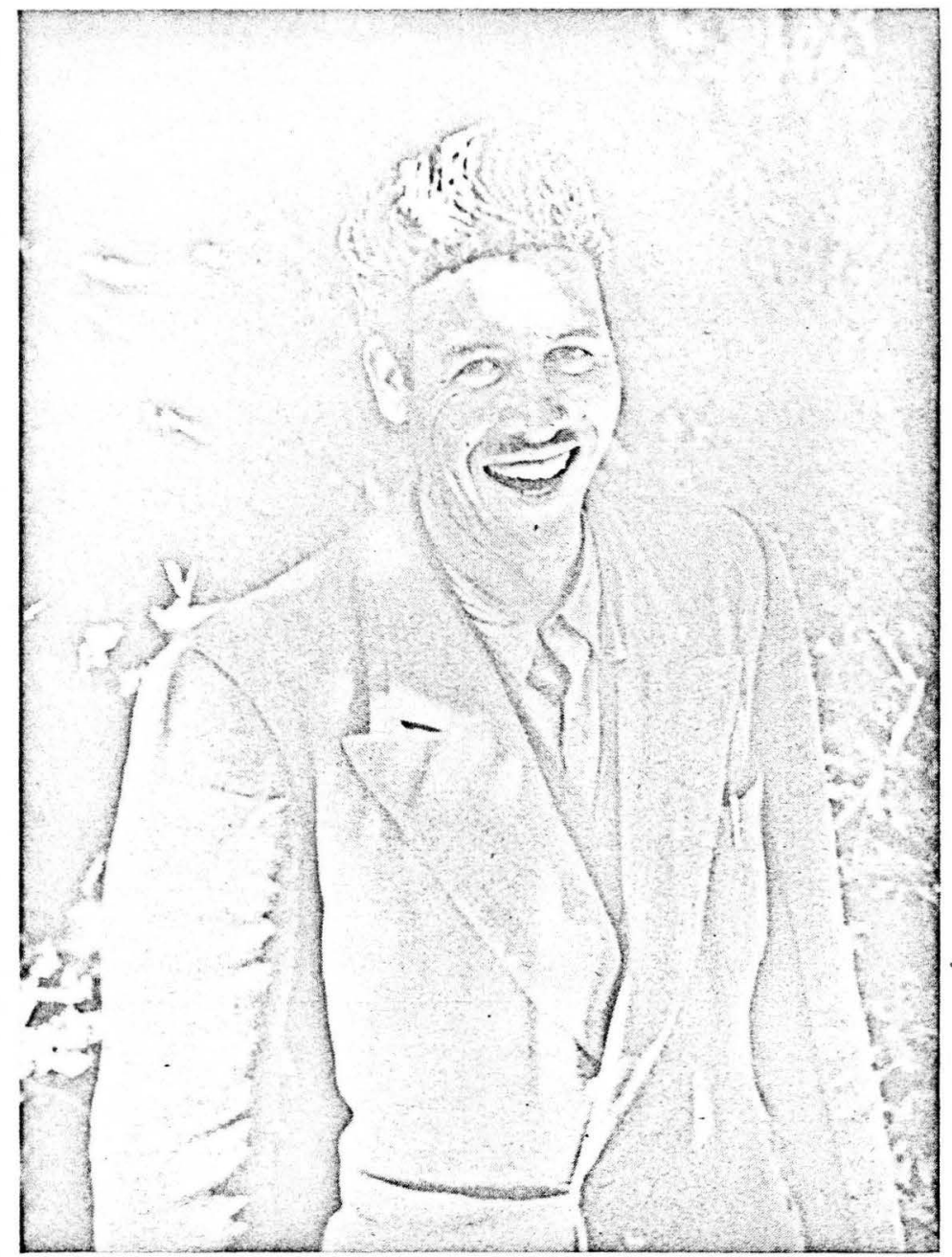

The Sub-Commissioner of Jurm, in Badakhshan. His work is largely paternal, including giving advice, settling quarrels and supervising labour as well as keeping an eye on foreigners inquisitive snouts of our photographic and cine apparatus.

Our departure from the province was eventful. After farewells to all our friends, we set out once more along the road to Khanabad, which was now flooded, so that we eventually bogged in three feet of water and had to use our LandRover's winch to pull ourselves out. There followed a nightmare drive over the same hairraising track by which we had come, but this time most of its inadequate width was taken up by herds of sheep, goats or camels, until we came to a place where for no apparent reason a large crowd had gathered. We eventually saw that half a mile further on a bridge had collapsed under the weight of one of the inevitably overloaded Afghan lorries, which had fallen some forty feet into a ravine. The District Gommissioner hurried up, a broad smile upon his face. "All is well. Only one person has been killed, and the lorry has been taken to Khanabad, where they will fix it somehow. The new bridge will insh'Allah be ready in six hours."

It was a remarkable demonstration: several hundred coolies were building a new bridge out of poplar trunks packed with straw, whilst others were carting enormous loads across the time we had the Kuchi caravans constantly with us. They travelled by night and we by day, and on one occasion we woke up to find that several score of these people had camped around us. That they were indeed rich was confirmed when they offered to pay for the cascara that we had given them for 'pains', and when they offered to buy a pair of binoculars. They spoke Pashtu amongst themselves, but all knew enough Persian to be able to speak both to us and to the crowd of Tajiks who invariably gathered around them. Their women hardly bothered to veil themselves, and the edges of their brightly coloured clothes were sewn over with coins. No objections were made to our watching a woman suckling her child, but the line was finally drawn at the unwinking eyes and long half-completed structure from a lorry on the Khanabad side to a waiting lorry on the other. Every so often there would be a loud cry of $A-a-a-a-h$ as a charge of dynamite sent a shower of rock and sand skywards. The work went on through the heat of midday, whilst we had a leisurely three-hour luncheon with the Commissioner in his shelter of leafy branches. Finally the bridge was ready. A vehicle-ours-was detailed to test its strength. As it reached the other side, a long cheer went up from the workers, who were obviously surprised at the quality of their handiwork.

"You are now in Kataghan," the Commissioner told us. "The road to Kabul is clear." With a grand gesture, he waved us on. 


\section{The Hazarajat of}

by WILFRED THESIGER, D.S.O.

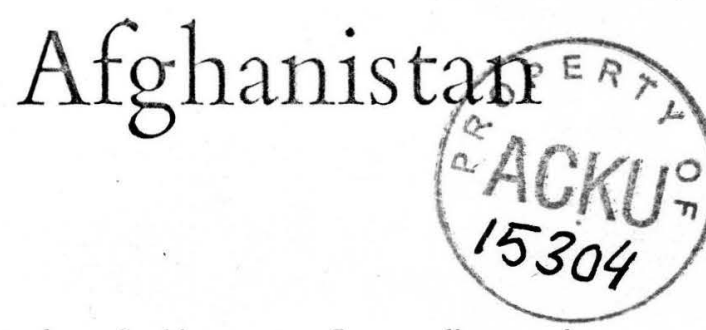

There is a tradition that the Hazaras who inhabit a large area in Central Afghanistan are the descendants of Mongols who were left behind in the I3th century by Jagatai, Jenghis Khan's son, or by Mangu, his grandson. Certainly the Hazaras are markedly Mongolian in appearance but the question of their true origin is a matter of controversy. Some still survive who are Mongolian-speakers, but most Hazaras speak a rather corrupt dialect of Persian, with an admixture of Mongol words. They are Shia Muslims, whereas the Pathans, Tajiks and Uzbeks who surround them belong to the Sunni sect of Islam, and this religious difference tends to isolate them from their neighbours. The area that they chiefly inhabit, known as the Hazarajat, includes Kuh$i-B a b a$, a rather uninspiring mountain range between 15,000 and 17,000 feet high with few peaks, which runs from east to west for about eighty miles and forms the western extremity of the Hindu Kush. Both sides of the range are seamed with a succession of valleys, and although the slopes of these valleys are generally steep they consist of earth and screes covered with thistles, coarse grass, rhubarb and cushion plants. The mountain is devoid of trees except for a few willows and poplars cultivated in the valleybottoms.

There are many springs on Kuh-i-Baba and streams in all the valleys. Wandering slowly on foot through this country I soon discovered that every fold and wrinkle in the ground to which water could be conducted was cultivated, with barley, wheat, peas, beans, lentils, vetch, clover and lucerne, and even the steep hillsides above the villages were sown with rain-grown wheat. In some of these mountain valleys the houses are strung out along the hillsides above a narrow ribbon of cultivation, farmhouse succeeding to farmhouse throughout the day's march; in others they are grouped in small villages. The houses are built of mud and stones and most of them are very primitive; usually they consist of three or four rooms and a dark narrow passageway. Most villages have watch-towers built either in the village itself or on the surrounding hills to guard the approaches.

Although the Hazaras are primarily agriculturalists many of them own large flocks of sheep and goats and some small, black, humped cattle. I was told that they supply nearly all the clarified butter or ghi which is sold in Kabul.

These Hazaras are obviously an extremely hardy race. I was constantly surprised that such large communities could live through the long winter months at altitudes where the cold is so intense and in a region where fuel is so scarce. They are also very industrious and struck me as good farmers with an understanding and love of their land.

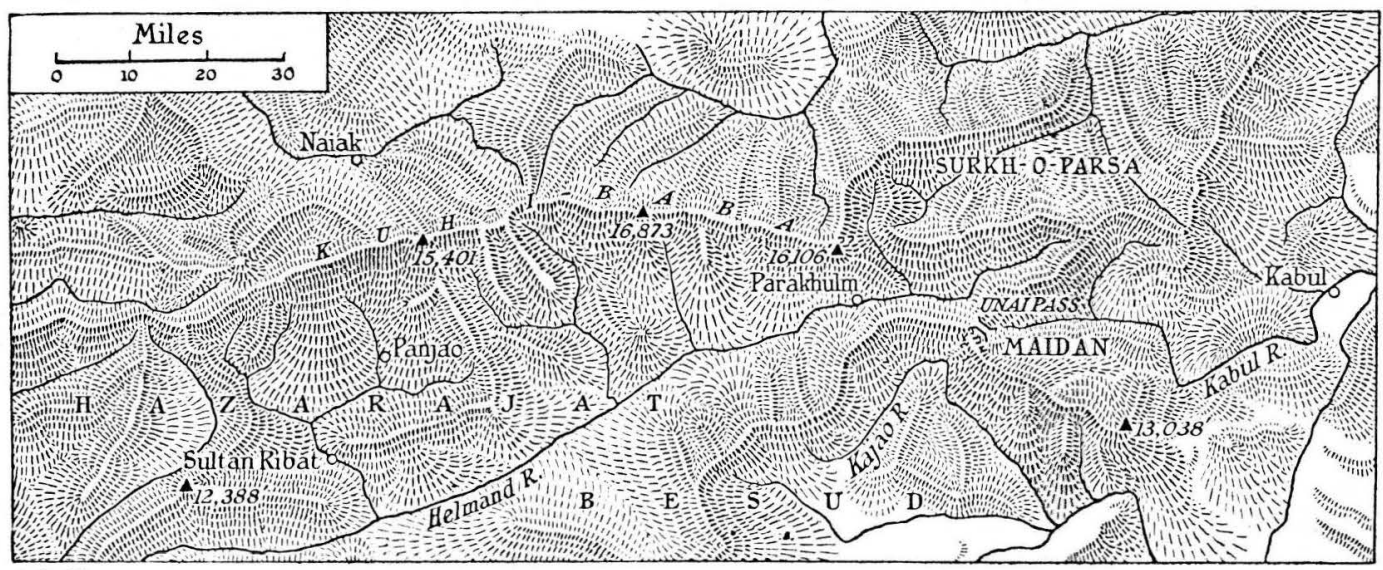

A. J. Thornton 


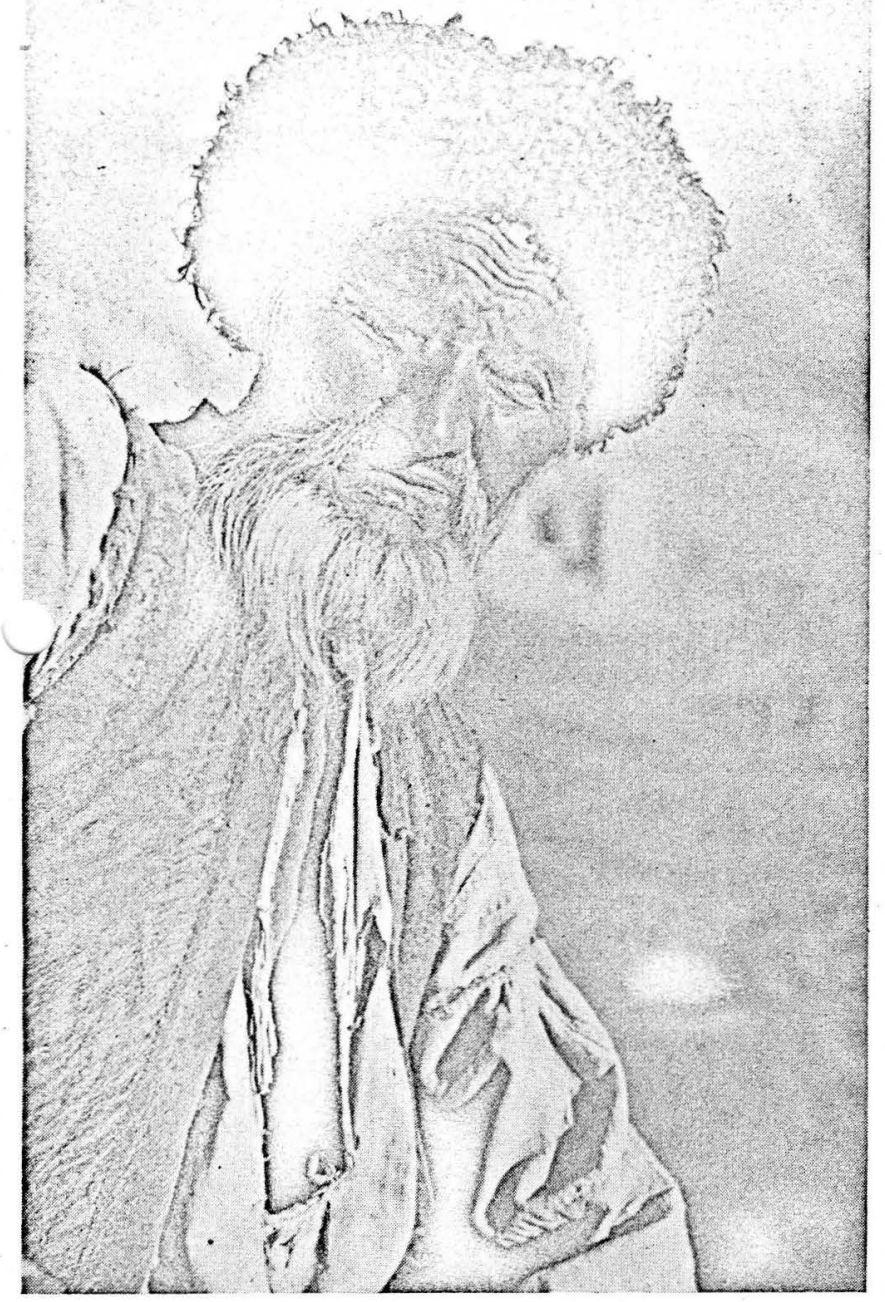

(Opposite) A Hazara tribesman, wearing the turban which is almost universal among them today. He might well be a descendant of the Mongol warriors who are supposed to have settled in Afghanistan in the Middle Ages. For some ninety years Hazaras served with distinction in the Indian Army: in 1904 their own regiment, the Io6th Hazara Pioncers, was raised at Quetta on the instructions of Lord Kitchener. Natural good shots, they won a great many rifle competitions. During World War I they saw active service in France, Persia and Mesopotamia, and many of them were decorated for gallantry. Thereafter it became more difficult to recruit them; in 1932-3 all Pioneer Regiments, including the Hazara Pioneers, were disbanded; and at the Afghan Government's request no more Hazaras were enlisted in the Indian Army. (Left) Until recently the Hazaras commonly wore lambskin caps similar to those seen in Central Asia, but now only older men do so. (Below) A waistcoat or jerkin, sometimes of leather, worn over a long cotton shirt, and trousers, is the usual summer dress, with a coat and top-coat in winter. The knitted woollen cap which the boy is wearing was not found by the author outside Surkh-o-Parsa

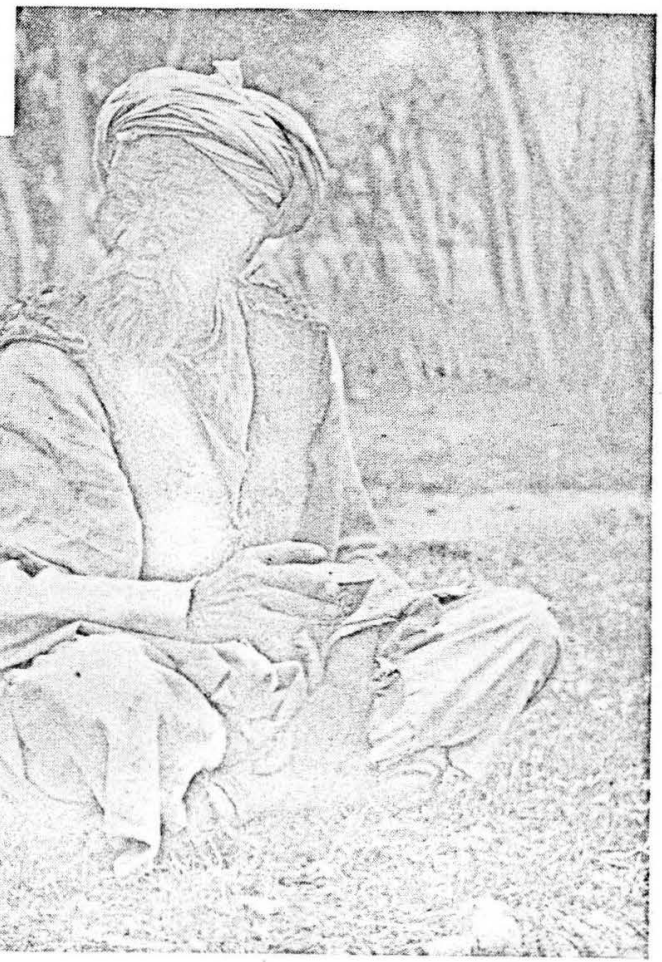




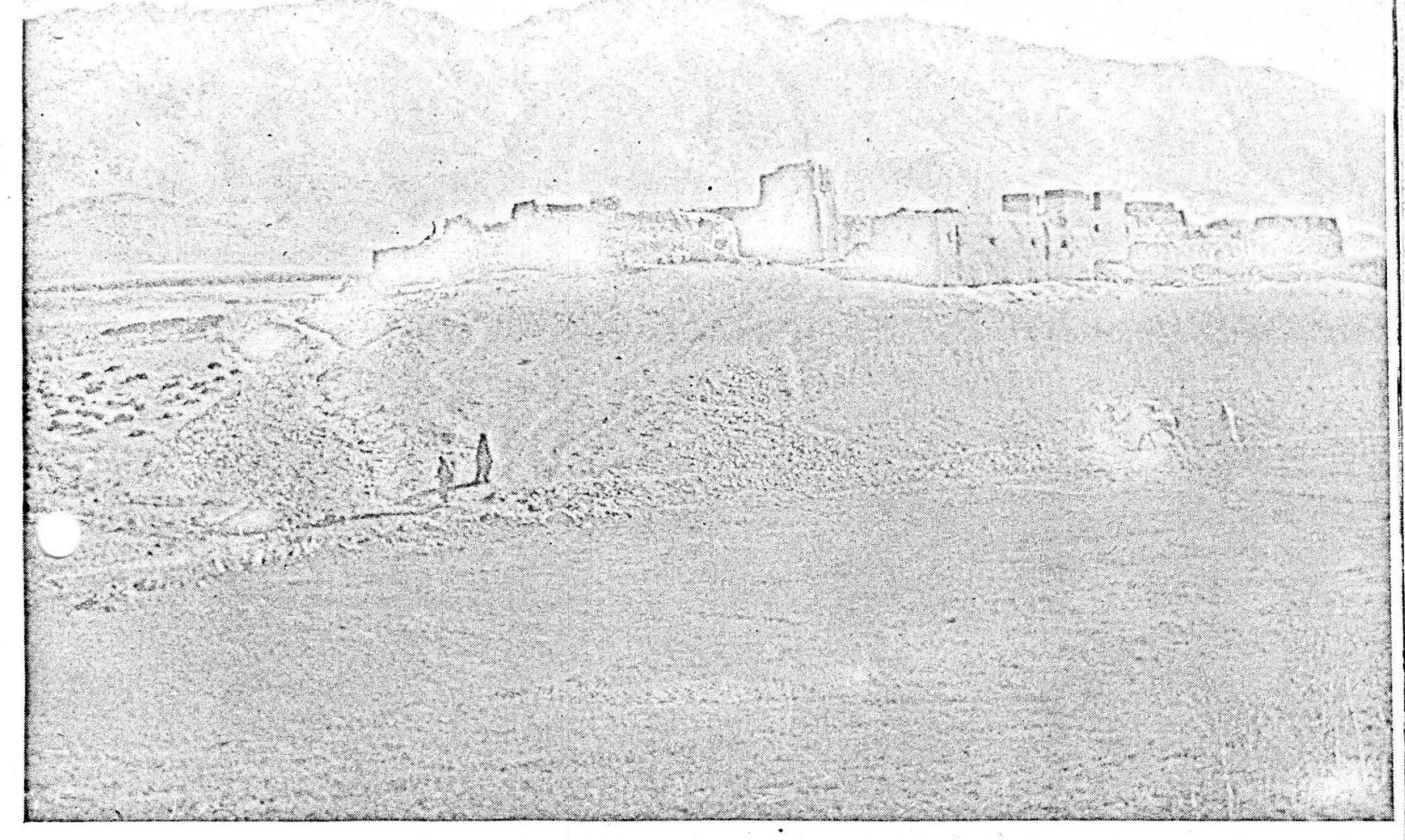

(Above) A Hazara village on a rise above the broad valley of the Helmand River. Beyond is the Kuh-iBaba with a few pockets of snow still lying on its upper slopes in September. The winter snowfall is the chief source of the streams along which are planted (below) the poplars used for building-timber

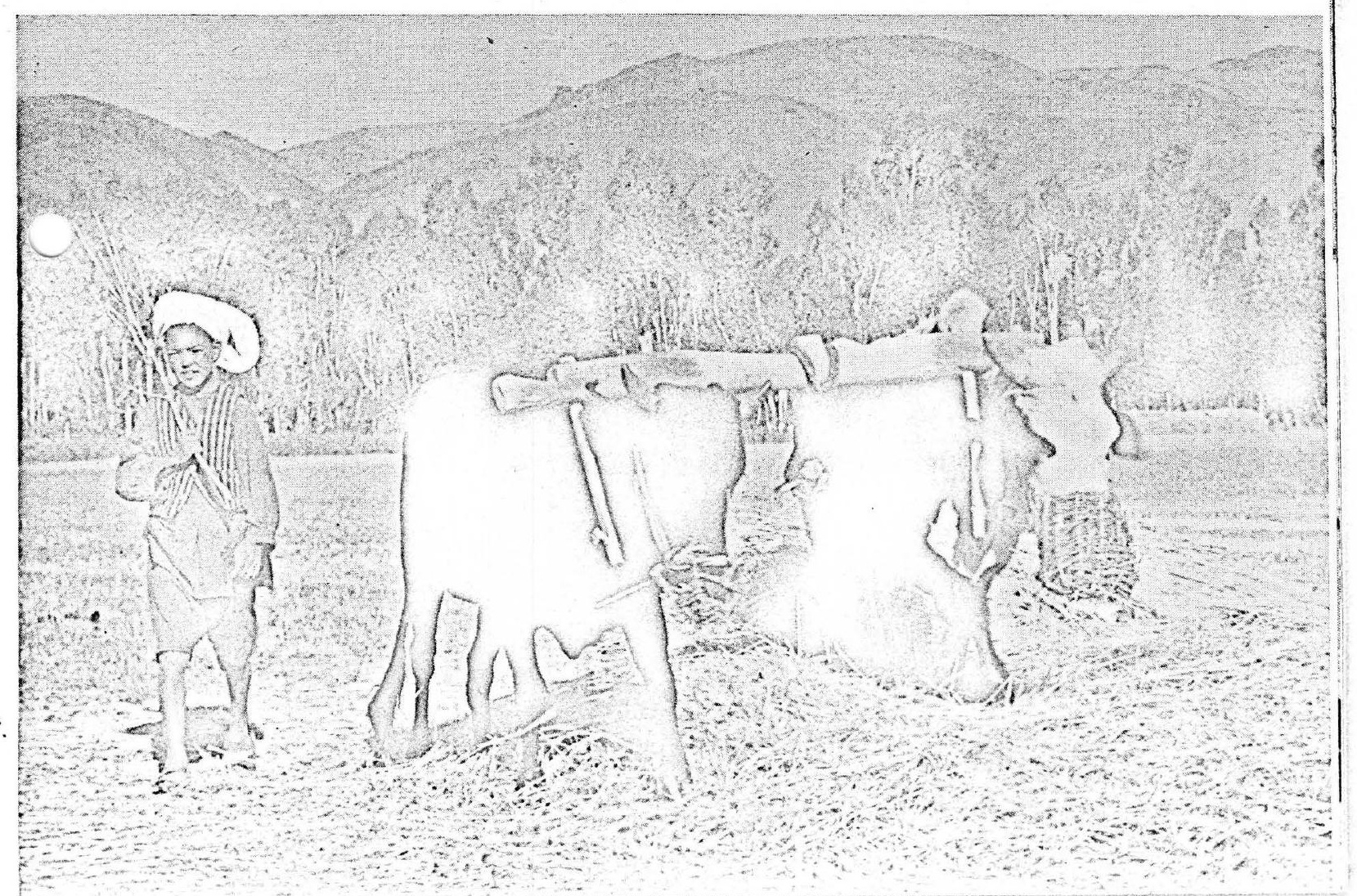




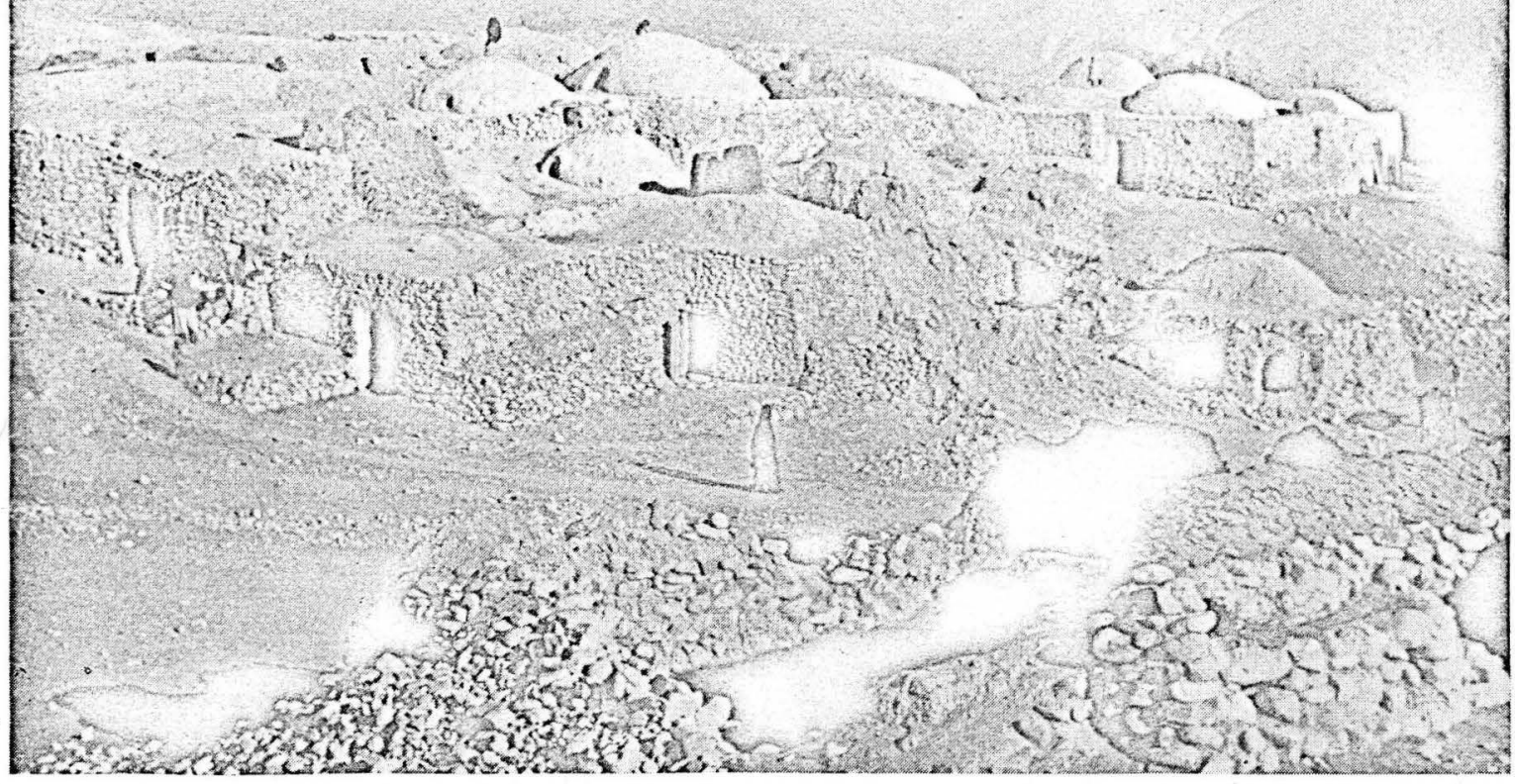

(Opposite) The Hazara chiefs usually live in large well-constructed forts. These are rectangular in shape with the rooms looking onto a central courtyard. Square or circular towers guard the outer corners and the single entrance is closed with a strong wooden gate. The flat roofs are of mud supported on beams of poplar. (Above) A village in the northern Hazarajat. Where timber is scarce the houses are roofed with domes built of stones projecting from the flat expanse of mud roof which may cover many houses. (Right) An old man bringing in a load of forage from the hillsides; piles of this can be seen in the foreground of the photograph opposite. The Hazaras spend much of their time collecting fuel and forage from the mountainsides to tide them through the winter months, when the cold in these villages at 8000-12,000 feet is intense

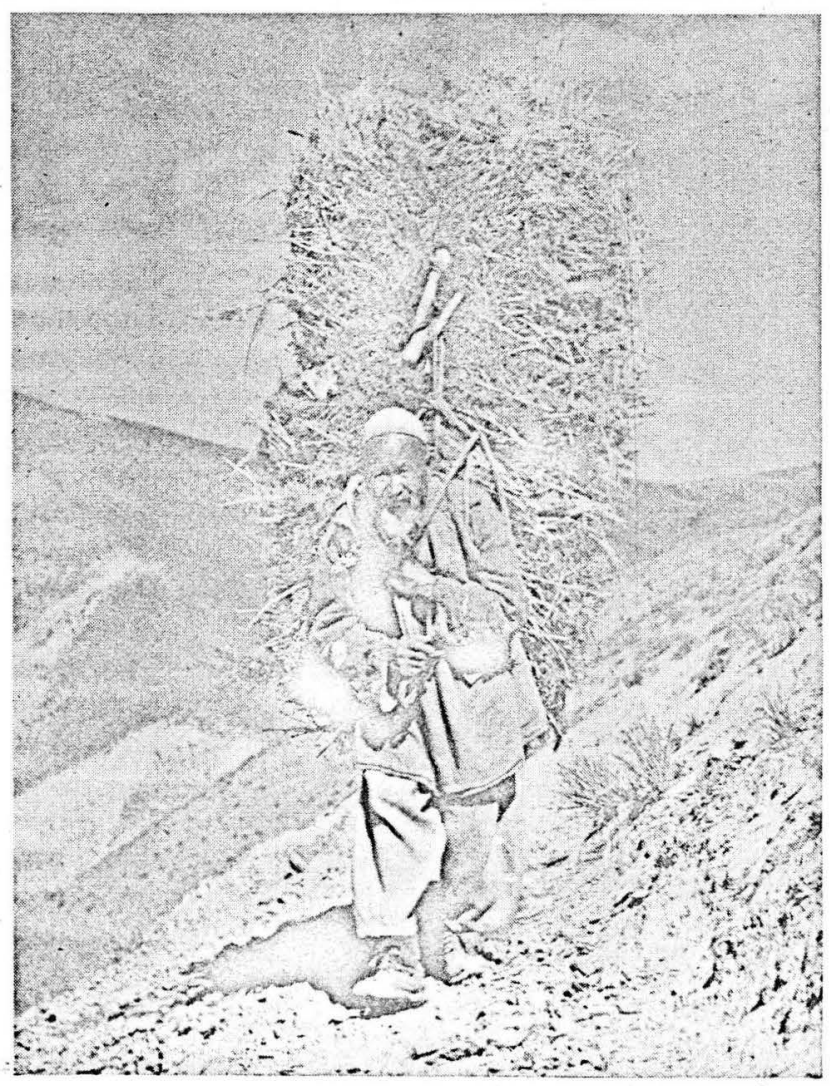


As well as owning large flocks of sheep and goats, the Kuchis bring with them from Pakistan (by donkey and camel) cloth, sugar, tea and other goods, which they trade with the Hazaras for grain and flour, on the way to their summer grazing grounds in the highlands of the Kuh-i-Baba. They travel to these up the valleys in the early summer and return again in the autumn

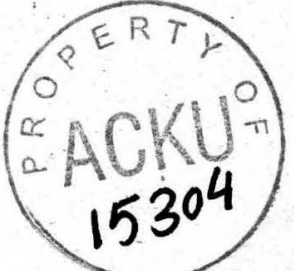

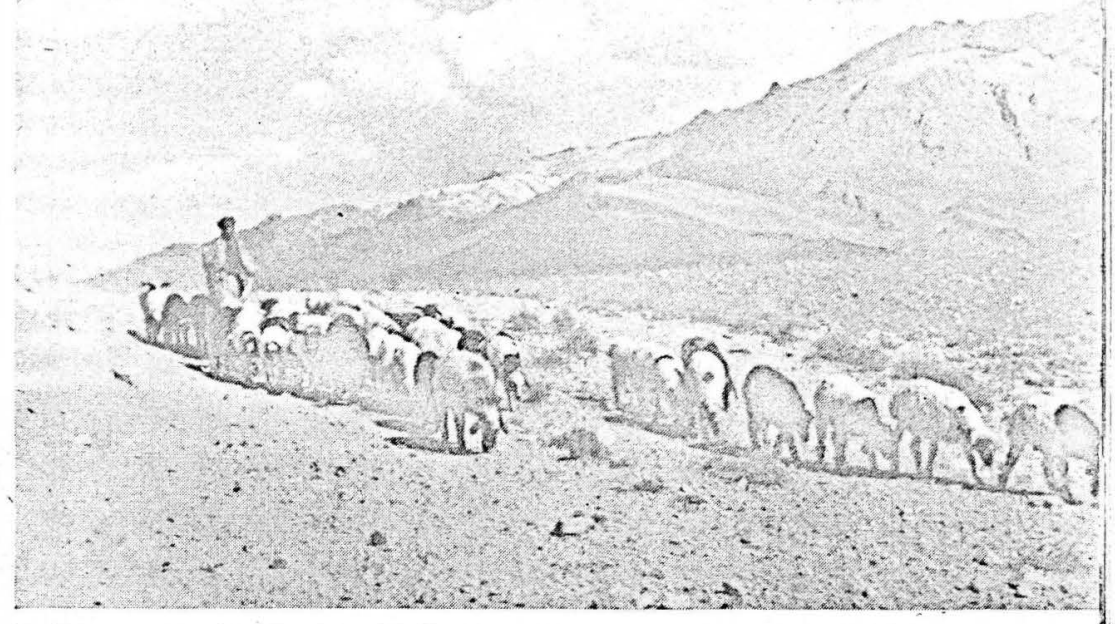
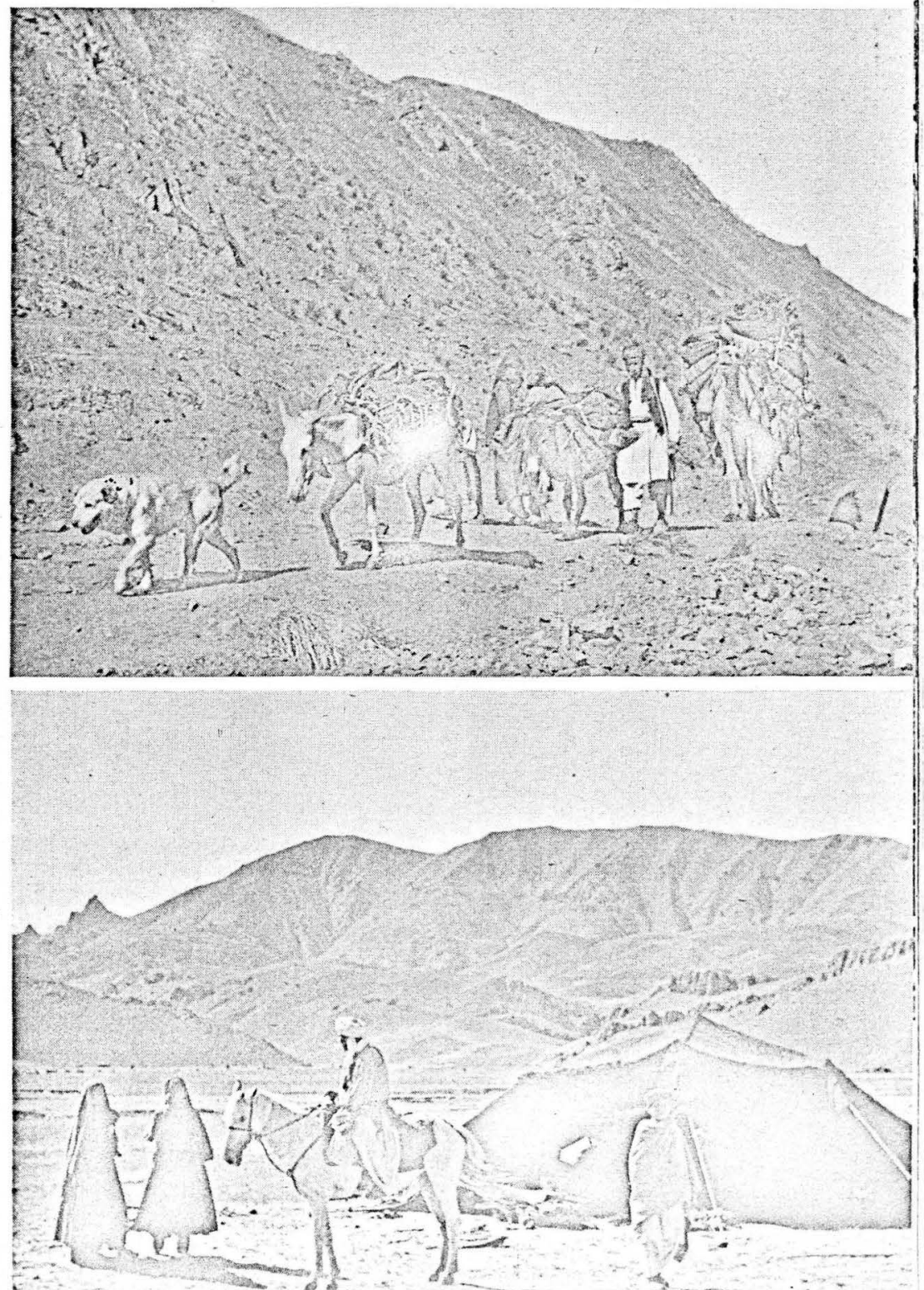


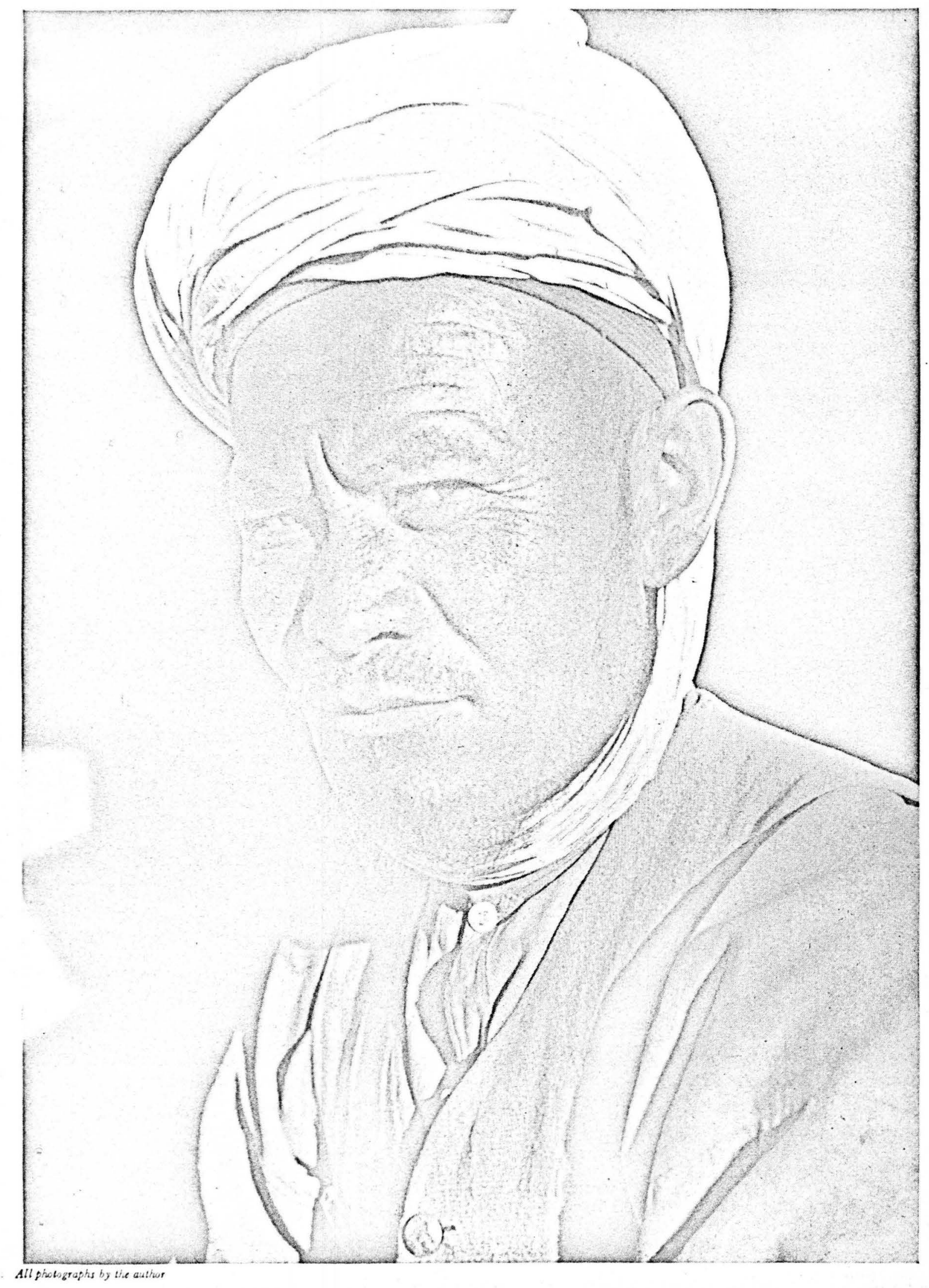




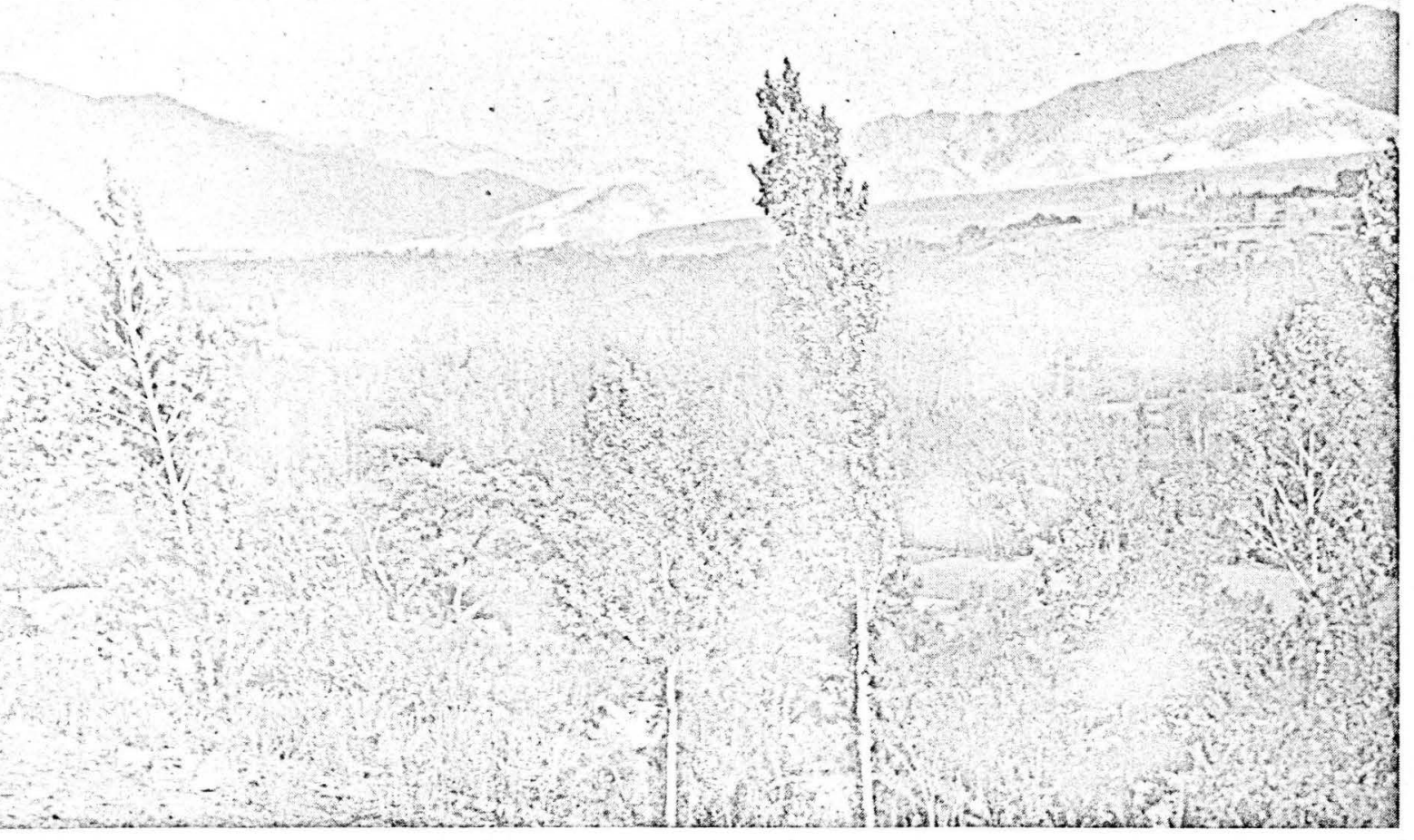

(Above) The Maidan district from which the author started his journey into the Hazarajat is a thickly wooded valley at the head of the Kabul River. It presents a striking contrast with the apparently barren hillsides of the Hazarajat (below); yet there each valley-bottom has its stream and cultivation

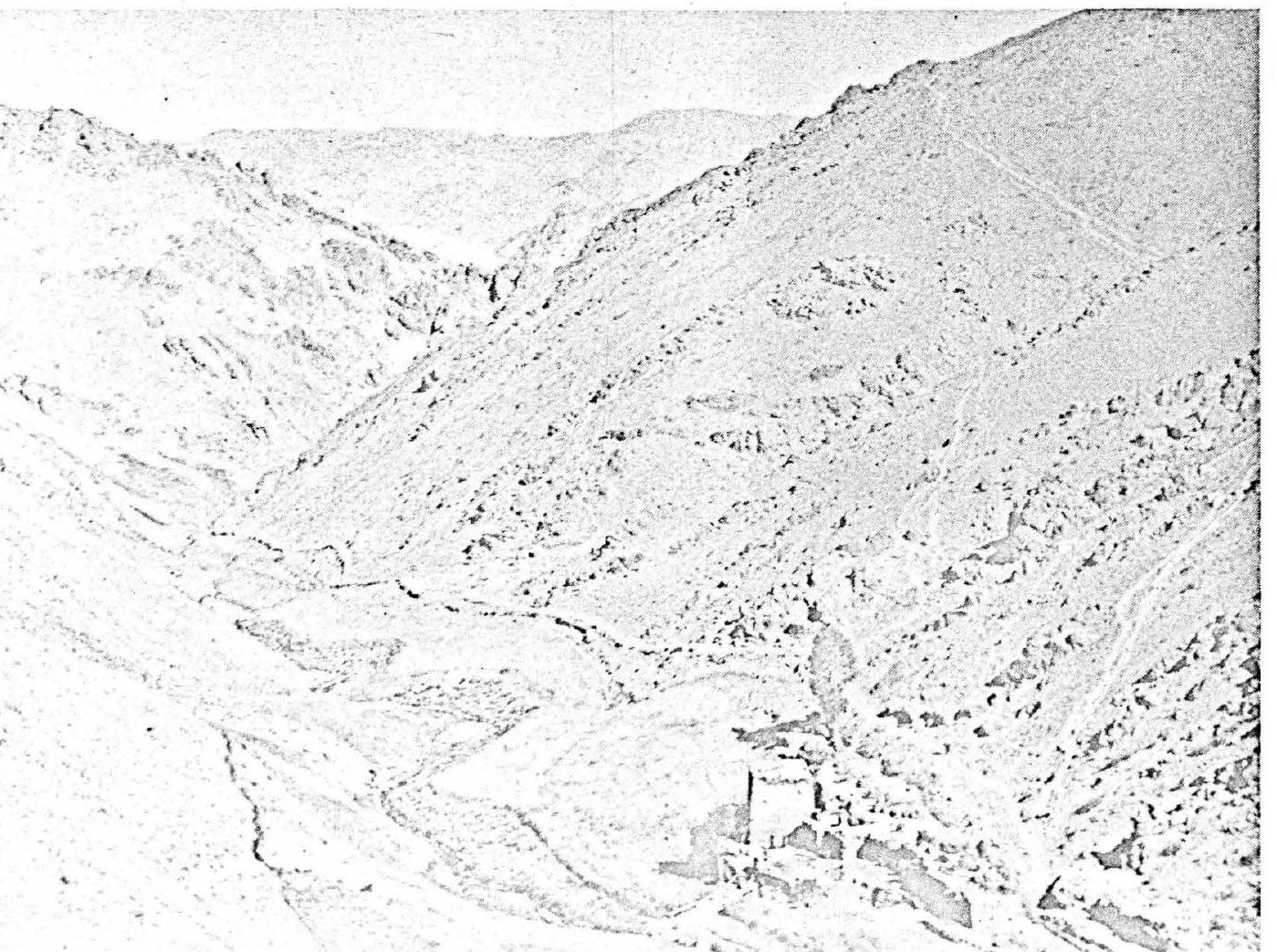




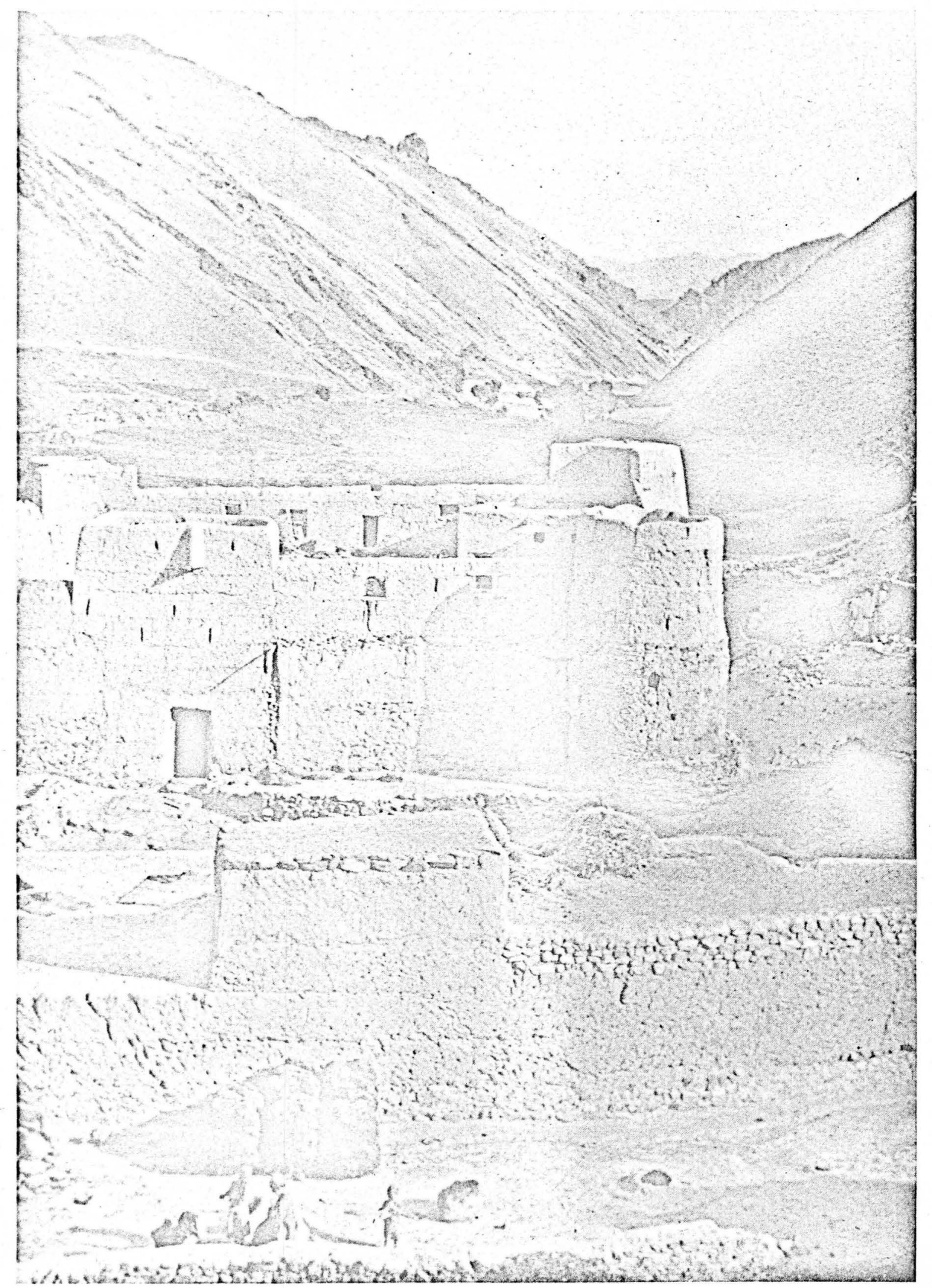




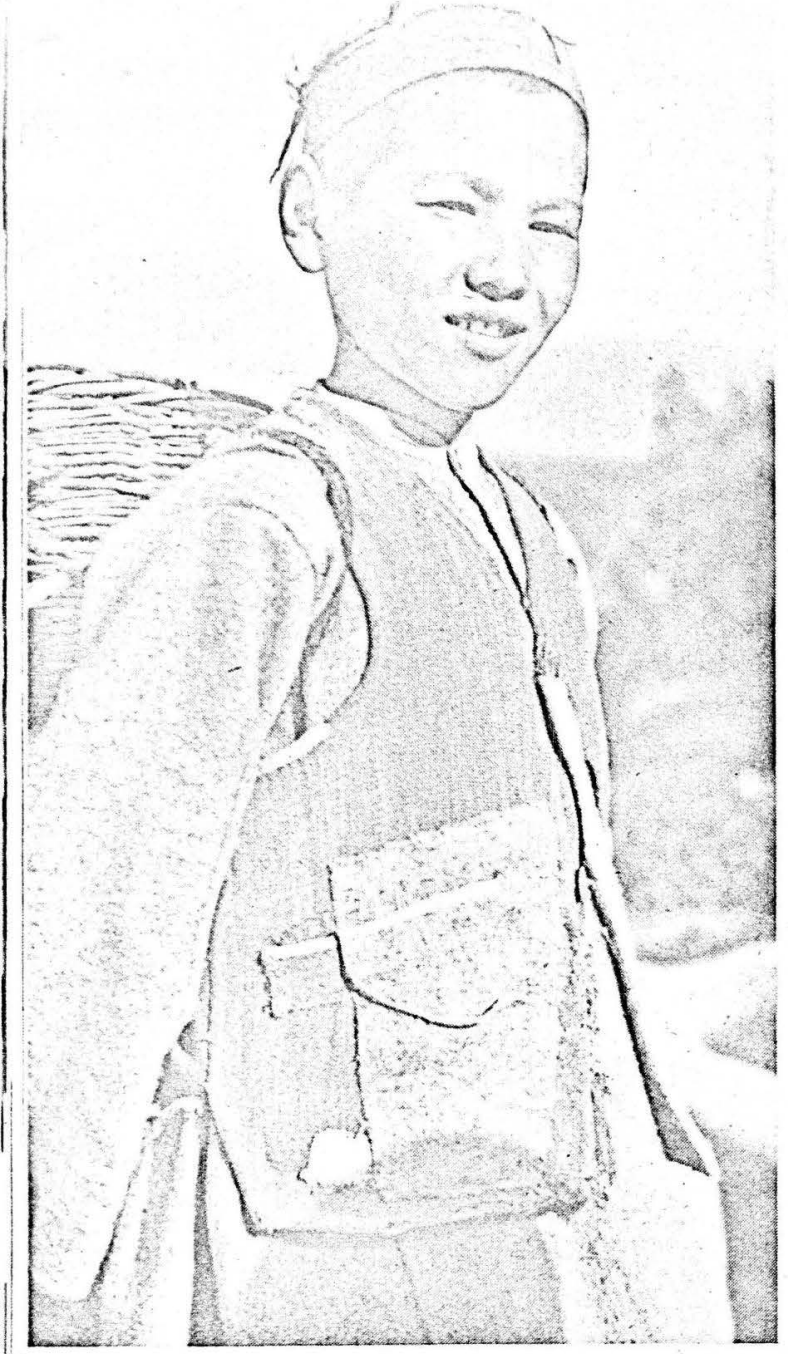

(Above) A fourteen-year-old Hazara boy whose Mongol descent is manifest in his features. (Right) A sixteen-year-old Kuchi lad. Unlike the Hazaras whom the author found hardy and industrious but inhospitable, the nomadic Kuchis, of Pathan stock, are friendly, amusing and gay. They are detested by the Hazaras, whom they in their turn despise though trading relations are nevertheless active between them

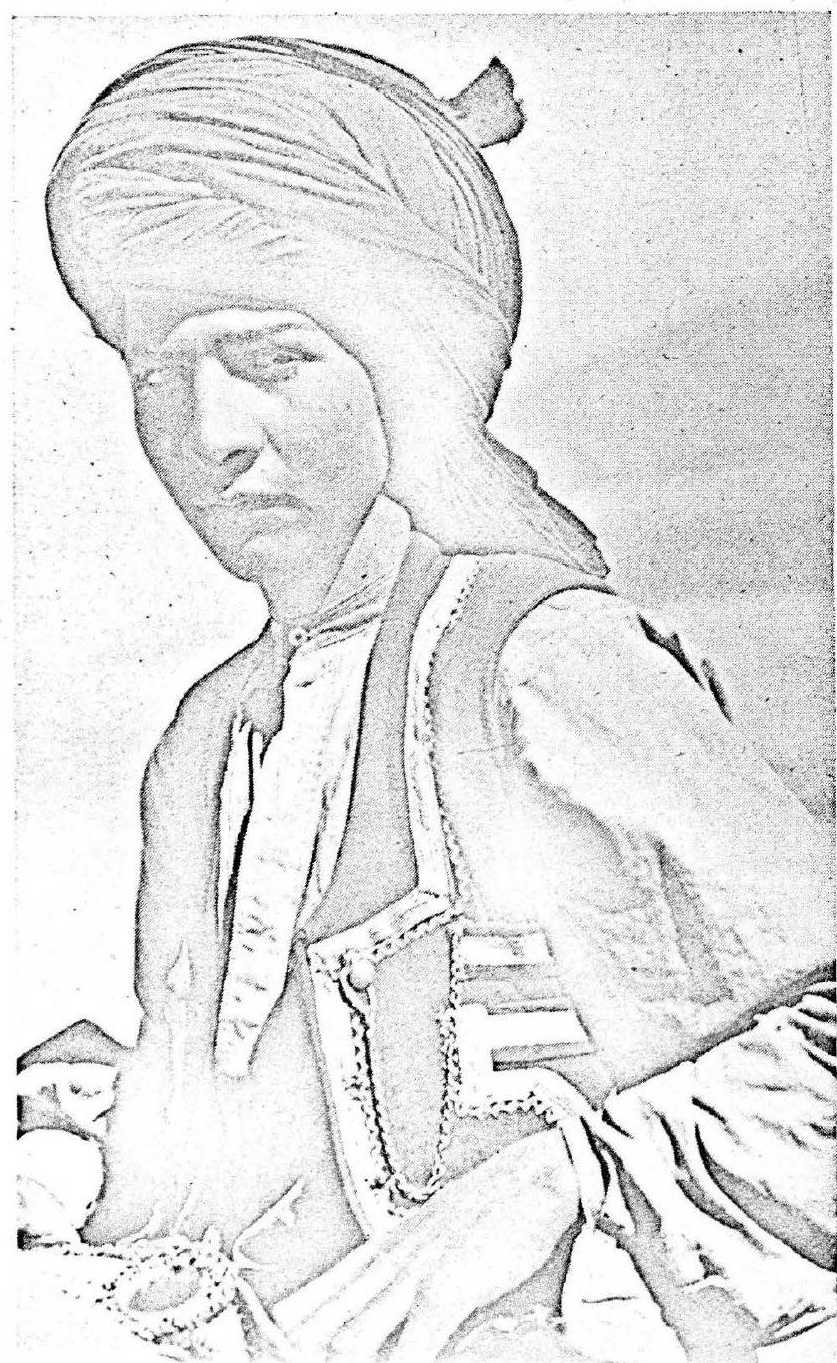

